\title{
Distal Arthrogryposis Type Six and Systemic Lupus Ery- thematosus, in a Girl: First Pediatric Case
}

\author{
Houda Nassih*, R El Qadiry, A Bourrahouat, and I Ait Sab \\ Department of Pediatrics, Child and Mother Hospital, Mohammed VI University Hospital Center, Caddy \\ Ayyad University, Morocco
}

*Corresponding author: Houda Nassih, Pediatric Ward, Department of Pediatrics, Child and Mother Hospital, Mohammed VI University Hospital Center, Marrakesh Medical and Pharmacy Faculty, Caddy Ayyad University, BP2360 Principal Ibn Sina Avenue, 575, Socoma II, PB: 40150, City of Marrakesh, Morocco, Tel: +2126-6816-6662

\begin{abstract}
Arthrogryposis type six is one of the distal arthrogryposes. It associates arthrogryposis of the hands and sensorineural deafness. Male-to-male transmission was observed. No gene has been identified to date. We report a unique case of a girl presenting with congenital arthrogryposis-like hand anomaly, sensorineural deafness, and acute onset of systemic lupus erythematosus (SLE).
\end{abstract}

\section{Introduction}

Arthrogryposis-like hand and deafness syndrome or distal arthrogryposis type 6 (DA6) is characterized by an arthrogryposis-like hand anomaly and a sensorineural deafness. It has been described in one family. Transmission occurs between male individuals. We describe a case of DA6 in a six-year-old girl who also had an acute onset of systemic lupus erythematosus (SLE). This case is -to our knowledge- the first to be described to date.

\section{Case Report}

The proband, product of a first-degree consanguineous marriage, a girl, with no family history of deformities, hearing loss, or auto-immune disease, who was born with arthrogryposis of the two hands, and had congenital deafness. Audiometric tests revealed a sensorineural deafness; after which, a cochlear implant was placed at two-year-old. As for her hand contractures, no treatment was applied because of family refusal. Fortunately, the child could cope with daily living needs. The girl developed a mild mental retardation on follow up. At the age of six-years, she had inflammatory polyarthralgia of big joins, treated symptomatically with anti-inflammatory medication with no improvement. Three months later, an acute onset of a cutaneous rash alarmed the parents. At examination, she had on top of bilateral hands arthrogryposis, a generalized discoid rash sparing the palms, and the soles of the feet. She had no other deformities. The parents reported photosensitivity and excessive hair loss. Markers of inflammation were very high (ESR $=76 \mathrm{~mm}$ the $1^{\text {st }}$ hour). We found leucopenia $\left(\mathrm{WBC}=3400 / \mathrm{mm}^{3}\right)$, normochromic normocytic anemia $(\mathrm{HB}=8 \mathrm{~g} / \mathrm{dl}, \mathrm{MCV}=85 \mathrm{fl}, \mathrm{MCHC}=$ $23 \mathrm{pg}$ ) with normal reticulocytes $\left(\mathrm{RET}=104000 / \mathrm{mm}^{3}\right)$, and no thrombocytopenia on blood count (was there thrombocytopenia?).

Cutaneous biopsy was performed, and histology confirmed the diagnosis of acute cutaneous lupus erythematosus. Screening for a cardiac, pulmonary, nephrological, neurological and ocular involvement was negative. Immunological testing was positive to anti-nuclear antibodies, anti-ds DNA antibodies. Meanwhile, complement, rheumatoid factor, anti-Sm antibodies, anti-Rnp antibodies were negative. Screening for antiphospholipid and Gougerot-Sjögren syndromes was negative. We started oral steroids (prednisone) at 15 $\mathrm{mg} /$ day and Hydroxychloroquine at $6 \mathrm{mg} / \mathrm{kg} / \mathrm{day}$, as well as a pediatric sunscreen. After two weeks, there was no more arthralgia and total remission of cutaneous symptoms. Steroid tapering was started three months later. After twelve months, the child was still asymptomatic;

Citation: Nassih H, El Qadiry R, Bourrahouat A, Sab IA (2020) Distal Arthrogryposis Type Six and Systemic Lupus Erythematosus, in a Girl: First Pediatric Case. Int J Rare Dis Disord 3:025. doi. org/10.23937/2643-4571.1710025

Accepted: November 10, 2020; Published: November 12, 2020

Copyright: (c) 2020 Nassih H, et al. This is an open-access article distributed under the terms of the Creative Commons Attribution License, which permits unrestricted use, distribution, and reproduction in any medium, provided the original author and source are credited. 
steroids were maintained at a low dose of $7.5 \mathrm{mg} /$ day. Her regular visual-field tests were unremarkable.

\section{Discussion}

Stewart and Bergstrom described in 1971 a 'new' syndrome of arthrogryposis-like hand anomaly and sensorineural deafness, where both features varied widely in severity. Two patients of the most recent generation had only the hand anomaly. Male-to-male transmission was observed. In a revised and extended classification scheme of the distal arthrogryposes, Bamshad, et al. (1996) referred to this disorder as distal arthrogryposis type $6[1,2]$. Our case is unique, firstly becauseit occrued in a female, and secondly because of the association to an acute onset of SLE. Cutaneous and rheumatologic manifestations revealed SLE. To our knowledge, this is the first case ever where DA6 is associated to SLE. This case can be easily confused with Rhupus syndrome, which includes lupus and rheumatoid arthritis. This condition can induce deformities of the hands resembling arthrogryposis. Butin our case the inflammatory arthralgia began no more than three months and can't explain the neonatal onset of the hand deformity.

Moreover, there was associated sensorineural deafness. These two features are the main characteristics of DA6 [3]. As for the association with SLE, we could not find any plausible explanation in literature. Management of SLE was based on international guidelines [4]. Significant improvement was obtained within a few months. Unfortunately, because of financial difficulties, no genetic sequencing was done.

\section{Conclusion}

Acute SLE in the course of DA6 could be easily mistaken as Rhupus, especially if it's a girl. Congenital onset of the hands' deformities, as well as the discovery of a hearing loss can rectify the diagnosis. Unavailable local facilities did not allow further investigations of this unique case.

\section{Contribution}

HN: Writing the paper, RQ, AB, IA: Final approval.

\section{Conflict of Interest}

All authors declare that they have no conflict of interest.

\section{References}

1. Bamshad M, Jorde LB, Carey JC (1996) A revised and extended classification of the distal arthrogryposes. Am J Med Genet 65: 277-281.

2. Bamshad M, Van Heest AE, Pleasure D (2009) Arthrogryposis: A review and update. J Bone Joint Surg Am 91: 40-46.

3. Stewart JM, Bergstrom $L$ (1971) Familial hand abnormality and sensori-neural deafness: A new syndrome. J Pediatr 78: 102-110.

4. Fanouriakis A, Kostopoulou M, Alunno A, Aringer M, Bajema I, et al. (2019) 2019 update of the EULAR recommendations for the management of systemic lupus erythematosus. Ann Rheum Dis 78: 736-745. 